\title{
O FUTEBOL NA IMPRENSA DE SÃO JOÃO DEL-REI (1930 -1955): A VOZ DE UMA PAIXÃO
}

KLEBER SACRAMENTO ADÃo

Universidade Federal de São João del-Rei / Brasil

kleber@ufsj.edu.br

Alex Witney Lima

Universidade Federal de São João del-Rei / Brasil

alexwitney@yahoo.com.br

\section{Resumo}

O presente artigo se propõe a discutir as relações entre a imprensa de São João del-Rei e o futebol no período compreendido entre 1930 e 1955. A partir de estudos utilizando os principais impressos circulantes na cidade, notamos que houve uma estreita relação entre o famoso esporte "bretão" e os jornais, que foram de extrema importância para a consolidação do futebol como o esporte mais popular da cidade histórica.

Palavras-chave: Futebol; Imprensa; São João del-Rei.

\section{EL FÚTBOL EN LA PRENSA DE SÃO JOÃO DEL REI (1930 - 1955): LA VOZ DE UNA PASIÓN}

\section{Resumén}

El presente artículo se propone a discutir las relaciones entre la prensa de Sao Joao del Rei y El fútbol en el período comprendido entre 1930 y 1955. A partir de los estudios que utilizan lãs principales formas que circulan en la ciudad, notamos que hube una estrecha relación entre el famoso deporte "Bretão" y los periódicos, que fueran de suma importancia para la consolidación del fútbol como el deporte más popular de la ciudad histórica.

Palabras-clave: Fútbol; Prensa; São João del Rei.

\section{THE SOCCER IN THE PRESS OF SÃO JOÃO DEL-REI (1930 - 1955): THE VOICE OF A PASSION}

\section{Abstract}

The present article intends to discuss the relationships between the press of São João del-Rei and the soccer in the period between 1930 and 1955. From studies using the main circulating printed papers in the city on, we noticed that there was a narrow relationship between the famous "Breton" sport and the newspapers, which were of extreme importance to the consolidation of the soccer as the most popular sport of the historical city.

Key-words: Soccer; Press; São João del-Rei. 


\section{Introdução}

O esporte em geral e o futebol em particular tem se tornado um campo vasto para os estudos de natureza histórica. Tal constatação é verificada a partir do significativo aumento da produção historiográfica relacionada ao tema (Santos e Silva (2006), Couto (2009), Mororó (2009), Júnior (2009), Pimenta (2009), Santos (2009), Moura (2010)), entre outros.

As referências teórico-metodológicas para o trabalho em questão foram baseadas em Norbert Elias, a partir de seus estudos sobre o processo civilizador e o esporte, em parceria com Eric Dunning ${ }^{1}$. Tais estudos consideram que as manifestações esportivas trazem em si elementos fundamentais ao conhecimento dos indivíduos e da sociedade no que convém a permanência e mudanças de hábitos e à vivência e controle das emoções.

Algumas categorias de análise propostas por Elias, tais como configuração, interdependência, equilíbrio de tensões, habitus, possibilitaram discutir a inserção do futebol em São João del-Rei - MG na primeira metade do século XX.

Segundo Elias (1970), para compreensão da sociedade torna-se necessário romper com o que chama de modelo tradicional que considera como sendo uma "visão egocêntrica da sociedade" para um modelo que perceba os indivíduos e grupos enquanto constituintes de "teias de interdependência ou configurações" de variados tipos os quais estão sujeitos a forças que os compelem, forças estas exercidas pelas pessoas sobre outras pessoas e sobre elas próprias. Configuração significa, pois, o padrão mutável criado por um conjunto de jogadores (no caso do estudo em questão: articulistas dos jornais, dirigentes de clubes e ligas de futebol ) não somente pelos seus intelectos, mas pelo que eles são no seu todo, na totalidade de suas ações em relações que sustentam uns com os outros. Este processo é dinâmico e assume diferentes conformações nas relações entre os indivíduos, grupo de indivíduos e sociedade. Ao discutir as relações entre imprensa e o futebol são-joanense, no período demarcado, tais conceitos possibilitaram a identificação dos níveis de representação presentes nos jornais sobre o futebol praticado pelos clubes, bem como o processo de condução do mesmo pelas ligas esportivas, que ao longo das décadas de 1930 e 1940, realizaram esforços na tentativa de organizar a sua prática na cidade.

Buscou-se identificar os níveis de tensão existentes entre imprensa e os atores do futebol local, caracterizado pela formação de um emaranhado de tensões decorrentes da interdependência dos jogadores, ou seja, dos agentes individuais, indivíduos e grupos que formam uma configuração. Tal relação de interdependência expressa-se hora enquanto aliados, hora enquanto adversários. Neste modelo proposto está contida uma espécie de equilíbrio flutuante, uma balança de poder que se desloca

\footnotetext{
1 Para abordagem mais completa ver ELIAS. N. \& DUNNING, E. (1995). Deporte y Ocio en el Proceso de la
} Civilización. México: Fondo de Cultura Economica, p. 33 - 81. 
para cima ou para baixo em função do movimento dos indivíduos, a partir de suas posições no campo do jogo social e cultural. (Elias, 1970).

Tais considerações explicitam a conformação de um novo habitus social, por considerar que esta sendo inserido no contexto sócio-cultural são-joanense um movimento de distinção dos usos e costumes marcados ao longo do tempo por uma certa "identidade-nós" (Elias, 1994), explicitada nesta sociedade nas representações construídas pela imprensa ao longo dos tempos. Este novo ordenamento configuracional será expresso no discurso jornalístico por uma certa tensão entre os costumes tradicionais e os chamados hábitos modernos. O destaque será dado para as novas diversões que gradativamente serão inseridas no espaço da cidade, nas primeiras décadas do século XX, com destaque para o teatro, o cinema e o desenfreado jogo de futebol. (Adão, 2001)

Este artigo apresenta alguns resultados decorrentes de projeto de pesquisa em andamento intitulado: "Nas Vertentes do Futebol: higienização, catalogação, fotodigitalização e organização dos acervos documentais das agremiações esportivas de São João del-Rei - MG, projeto este desenvolvido com recursos da Fundação de Amparo a Pesquisa de Minas Gerais (FAPEMIG), cujo objetivo maior é promover o resgate e preservar a memória do futebol no município e região.

Ao tecer uma narrativa sobre os acontecimentos relativos ao futebol trazidos ao público leitor pela imprensa local estar-se-á discutindo as relações estabelecidas pelos jornais, a partir da pena de seus articulistas, com as agremiações e sujeitos promotores do futebol na cidade.

Importa destacar que o pesquisador dos jornais trabalha com o que se tornou notícia, o que por si só já abarca um espectro de questões, pois faz-se necessário dar conta das motivações que levaram a publicar determinado assunto. Sendo assim ao optar pela utilização dos jornais como fontes históricas concorda-se com o Cury (1998) quando a autor afirma que os jornais carregam em si, de forma mais variada possível, os aspectos culturais do tempo em que eram publicados. E, através de suas páginas, os intelectuais manifestavam suas idéias, deixando nelas impressas sua passagem pela história do país. Neste contexto, é intento através da leitura dos jornais locais que participavam da vida cotidiana da cidade, entendermos mais afinco as relações que se davam entre o esporte bretão e a sociedade sãojoanense, pois concorda-se também com Almeida (1983), quando o autor afirma que o jornalismo regional se propõe a representar uma determinada área geográfica, já que a mídia interiorana incorpora elementos típicos da cultura local na transmissão das informações, aproximando-se então da identidade regional. Por isso mesmo, esse tipo de jornalismo retrata eventos daquele espaço ao registrar os fatos que falam da realidade de seu público-alvo. Assim sendo, o acesso a tais publicações pode proporcionar as condições necessárias para a construção de momentos históricos não registrados oficialmente pelos clubes. Neste contexto, para a realização da pesquisa proposta foram utilizados os três principais jornais 
locais circulantes no período. A escolha por tais jornais se deu devido a importância que cada periódico assumiu no cotidiano da cidade no século passado.

O primeiro jornal investigado foi “A Tribuna”, fundado em 18 de julho de 1914 cuja circulação se deu até 1938. De acordo com seus articulistas o jornal apresentava-se como modernizador, embora apegado as tradições e representações da cidade colonial das quais se fazia arauto.

O segundo jornal analisado, denominado "O Correio", foi fundado em 08 de setembro de 1926. Tinha como finalidade ser o órgão de divulgação do Partido Republicano Municipal (PR). Este jornal, de abrangência regional, com fortes tendências políticas, era direcionado as elites do município, porém, em pouco tempo tornou se um jornal direcionado a população em geral. O jornal O Correio circulou quinzenalmente pela cidade entre 1926 e 1960.

Utilizou-se também como fonte de consultas o jornal "Diário do Comércio" fundado em 08 de março de 1938. Sua criação pela Associação Comercial de São João del-Rei teve como intuito ser o informativo oficial das indústrias e do comércio são-joanense. Este jornal de circulação regional esteve presente no cotidiano da cidade de 1938 a 1961. O periódico foi fundado durante o Estado Novo e dizia-se apartidário, porém deixava clara sua luta pela democracia e sua simpatia pelo Partido Social Democrata (PSD).

As consultas aos periódicos foram realizadas no Instituto do Patrimônio Histórico e Artístico Nacional (IPHAN) de São João del-Rei, e ao se realizar a pesquisa optou-se por utilizar, dentro do período pesquisado (1930 a 1955), todos os exemplares disponíveis. Tal escolha se deu pelo fato de ser busca atingir um maior numero possível de relatos acerca da presença do futebol no cotidiano da cidade, uma vez que não se tratavam de periódicos voltados apenas para o noticiário esportivo.

Observa-se, a princípio, que a maioria dos periódicos pesquisados buscavam estreita relação com o futebol da época. Assim sendo, o intuito foi identificar como os principais periódicos sãojoanenses tratavam o futebol em suas publicações: notícias que, na maioria das vezes, deixavam de ser imparciais para se tornarem a "voz de uma paixão."

\section{O Esporte na Imprensa São-Joanense}

Nos jornais que circulavam em São João del-Rei eram narrados e expostos os fatos acerca da vida da cidade, bem como as representações reais ou idealizadas que dela se tem. Eram comuns anúncios informativos, editoriais, publicidades que apresentavam a cidade como progressista e em franco desenvolvimento, embora também exijam das autoridades providências com relação ao lixo abundante, a violência, a gatunagem, o número de mendigos circulantes pelas ruas do centro e a jogatina sem fim que disputa espaço com o sagrado nas festas populares como as que se realizam no bairro de Matosinhos (Festa em Matosinhos, A Reforma, 31/05/1917, num. 22, ano IV, p.2). 
O cenário que se descreve através da pena do cronista parecia favorável à introdução dos esportes no cotidiano da cidade à medida que este era sinônimo de moderno e reforçador do conceito de sociedade civilizada e progressista. O jornal "São João d’EL-Rey" em crônica titulada “O Commercio" expõe um cenário favorável a essa relação.

(...) O laborioso e o honrrado comercio local em cujo seio as quebras, pela raridade que se registrão constituem acontecimento notável e de sensação cresce e prospera, ao que apuramos em ligeira enquête com os principais comerciantes. (...) Abastecem a cidade o município o oeste numerosas casas atacadistas de gêneros, importantes estabelecimentos de fazendas, artigos de moda, armarinho, casas especiais de calçados, de ferragens, de machinimismos e instrumentos para a lavoura, de louça e de materiais de construção. Há aqui vários cafés, confeitarias, cinemas, associações recreativas e beneficentes (SÃO JOÃO DEL-REY, 25 de agosto de 1920, ano I, num. 24) (grifo nosso).

Nas primeiras décadas do século XX, ao contrário do que ocorria com a imprensa no Rio de Janeiro (Melo et alii, 1997), o esporte não recebia um tratamento especializado a ponto de ter um periódico ou mesmo colunas e seções a ele destinadas. Contudo, o assunto não deixava de ser objeto da fala e comentários dos cronistas.

Assim as poucos as práticas esportivas assumem importância na sociedade, vão ganhando espaço e sendo matéria de discussão, nas esquinas, cafés e espaços públicos. Essa percepção é apresentada em editorial do jornal Acção Social onde ele comenta em meio à sensação de exaltação e apreensão o papel que a imprensa vem assumindo neste iniciar do século XX.

(...) Resulta daí que o papel do jornal se transforma (...) Limitava-se, outrora a registrar os factos do dia-a-dia; mais tarde compreende os debates políticos. (...) Agora sua funcção é encyclopedica: O jornal é o maior literário scientífico, jurídico, político sociaes da massa popular. (...) Nada do que é humano lhe escapa do jornalista um ensino universal.

Infelizmente o nível da Imprensa não te leva à medida que cresce a sua importância (...) pois o leitor quer ser informado o mais depressa e o mais abundantemente que seja possível, de sorte que (...) obrigam a imprensa a trabalhar às carreiras, febrilmente, sem verificar as noticias, sem preocupar, escrupulosa exatidão, sem reflexão nem ponderação rigorosa (Sobre a Imprensa. AÇÃO SOCIAL. 21 de março de 1915, ano I, num. 03, p.1).

Os jornais em sua maioria informavam sobre a criação de clubes e associações recreativas, os jogos e eventos realizados, sempre em caráter festivo, daí o nome festa esportiva, com a participação das recém criadas agremiações. As excursões e encontros esportivos eram realizados com clubes da cidade, da região e da capital mineira. É o que nos informa o colaborador que assina sobre o pseudônimo "Judex" no jornal “A Tribuna” em edição 1919: 
(...) Seguiu-se hontem para Bello-Horizonte, a fim de ultimar o match - taça Souza Cruz - a equipe, a ultima hora organizada pelo Atlhetic Club desta cidade para baterse com seu competidor O Atlhetico Mineiro, de Bello-Horizonte.

(...) No qual prevemos uma derrota para os nossos sympathicos e valorosos jogadores do alvi - negro (...).

O comparecimento do Atlhetic Club, em campo de seu adversário constitui uma victória moral pois assim mais uma vez, vem comprovar sua lealdade e heroísmo não fugindo da lucta embora com competidor muito mais forte. (...) applaudimos sua atitude digna pis caso seja abtido será um heroe e não um covarde (A TRIBUNA, 05 de outubro de 1919, num. 275)

As dificuldades iniciais relativas às disputas com times das cidades vizinhas citam os jornais, ocorreram, por conta das condições ruins das estradas, das intempéries, sendo algumas destas viagens realizadas a cavalo.

Em nota assinada por um colaborador, na mesma edição do jornal A Tribuna, é narrada uma partida amistosa acontecida na Villa Resende Costa entre o time local, Rezendino F. Club e o Xavierense Club. Eis a nota:

Realizou-se no dia 16 do corrente, em Villa Rezende Costa, um amistoso match de foot-ball, entre o Rezendino F. Club d'quella e o Xavierense Club de S. Francisco Xavier, (...) Às 10 horas da manha deste dia chegaram à villa depois de longa viagem à cavallo os jogadores do xavierense e mais diversas pessoas que o acompanharam. À uma hora da tarde, se dirigiram para o campo os dois teams acompanhados pela banda de musica e grande massa popular. (...) Termina o jogo da seguinte maneira Xavierense 3, Rezendino 1.(...) por aqui pode-se ver o progresso do foot-ball. Antes isso!

A imprensa também da ênfase à rivalidade entre as recém criadas associações esportivas não deixando de manifestar sua predileção por este ou aquele clube, demonstrada pela forma na qual é dado o destaque no resultado obtido ou na participação ou de determinado clube nos jogos de que toma parte. A tomada de posse de diretorias de clubes, findo mandato, eram noticiados sendo, vez por outra acompanhados de bailes e recepções aos convidados denotando o que os cronistas denominam de programa festivo associando o esporte à festa, enquanto sociabilidade em processo de consolidação como um novo habitus dessa sociedade.

A esse respeito o periódico "Cine-deal” órgão noticioso, e de propaganda do Cinema Ideal e do comercio local, comenta a criação do "Brasil Volley Ball Club", sociedade esportiva que tinha como finalidade no esporte "delicado e interessante" volley ball. A iniciativa se deu segundo o jornal graças a um grupo de senhoritas da sociedade local. Na noite do dia 28 de julho de 1919 realizou-se assembléia extraordinária na sede dos empregados do comércio com finalidade de eleger a diretoria do citado clube. O fato curioso é que apesar do clube ter, segundo as notas do jornal, sido fundado por um grupo de senhoritas sua diretoria é constituída por homens, tendo como presidente o Tenente Edgard de 
Oliveira e o diretor de esportes o Doutor Hebert de Vasconcellos (Sports. Jornal Cine-Ideal. 03/08/1919, num 02, ano I, p.2).

As narrativas acima expostas contribuem para o entendimento sobre o papel da imprensa na vida cidade, ou seja, no seu cotidiano. Ainda que a população não soubesse ler os fatos narrados e comentados pelos jornais eram transmitidos através do público leitor alfabetizado. Outro possível mecanismo de divulgação das notícias se dava através dos comentários feitos pelos leitores nos lugares públicos tais como cafés, bares, casas de comércio, ruas, esquinas e praças. Dessa forma, as práticas esportivas eram levadas até população em geral ao mesmo tempo em que, contribuindo para sua divulgação e ganhando novos adeptos.

\section{Futebol e Imprensa: uma íntima relação}

Os principais periódicos de São João del-Rei, dentre eles: "Diário do Comércio" (1938 - 1965), “O Correio" (1926 - 1960) e "A Tribuna" (1914 - 1938) dedicavam um espaço em suas publicações para tratar do futebol, esporte mais popular na cidade durante o período estudado. Um exemplo importante, é que todas as ligas esportivas existentes na cidade, entre 1930 e 1955, tiveram um jornal "parceiro", o qual possuía a responsabilidade de divulgar aos leitores as principais resoluções das entidades.

A ASEA (Associação São-joanense de Esportes Atléticos), fundada em 1932, publicava todas as decisões tomadas em cada reunião de seu conselho esportivo no jornal "Folha Nova": "Folha nova tendo sido indicada para órgão oficial da ASEA, todas as notícias publicadas com o título "oficial” são considerados como tal, provendo diretamente da secretaria da Associação”. (Jornal FOLHA NOVA, 13 de Março de 1932. Ano: I n. 02, P. 2). Apesar dos esforços empreendidos para a organização do futebol local, a associação teve curta duração. Os motivos de seu término não foram totalmente esclarecidos pela imprensa da época, contudo, em sua edição de 1933, o jornal O Correio ${ }^{2}$ critica a falta de reconhecimento, por parte dos clubes, ao trabalho da entidade até então: “(...) Em crônica posterior procuraremos demonstrar como foi proveitoso para nosso futebol o campeonato instituído pela Associação São-joanense de Esportes, infelizmente mal compreendido nos seus fins e desvirtuada pelo clubismo, que nasceu e criou raízes como uma erva daninha.”.

O certo é que a ASEA não vingou e em 1938 surgiu uma nova esperança. Foi fundada a LEOM (Liga de Esportes Oeste de Minas), que deveria gerir todo o esporte, não apenas de São João del-Rei, mas de toda a região, como noticiou o jornal O Correio ${ }^{3}$ do respectivo ano: “(...) sabemos (...) ter-se fundado sob o apoio do capitão Adalberto Mendes e dos clubes locaes uma nova sub-liga, destinada a

2 O correio, 28 de outubro de 1933, Anno VII: Numero: 368

3 O correio, 8 de Maio de 1937, Anno XI : Numero 552 
congregar, controlar e dirigir, nem só as atividades esportivas são-joanenses como do oeste mineiro $(\ldots)$.

No seguimento da mesma reportagem, notamos que diferentemente da ASEA, a criação da LEOM não empolgou tanto os amantes do "Foot - Ball":

temos observado com decepção, que as tentativas anteriores fracassaram ante o predomínio de uma política pessoal, mas desperciva que construtiva (...). É patente a nossa inferioridade se considerarmos o progresso que se verifica nos diversos sectores de nossas atividades culturais. (...)Só a criação de uma liga de esportes prestigiada por todos os figurantes, poderá levar-nos a um valor real que nos nivele ao nosso elevado grau de desenvolvimento e cultura geral (...).Com uma liga permanente, campeonatos regulares e jogos contínuos, haverá o aperfeiçoamento dos playeres, pelas varias razoes de estímulos resultantes haverá prechos mais interessantes pela melhor técnica e haverá mais educação do gosto com motivos de maior atracção e interesse para os afficionados.

É preciso o apoio oficial que falta ao nosso esporte, ante, porém, é preciso organização. Vida a sub-liga e morte ao clubismo.

Durante o em que esteve em atividade a Liga de Esportes Oeste de Minas tornava público seus atos administrativos e informes nas edições do jornal Diário do Comércio, tal como a comunicação a seguir: "Pelo conselho resolvendo casos omissos ficou deliberado que: as mudanças de residência de qualquer jogador desta cidade sem caráter transitório é motivo de cancelamento da sua inscrição.”. (Jornal DIARIO DO COMÉRCIO, 18 de Junho de 1939. Ano. II, n. 384, p. 5).

Seguindo as determinações emanadas da política do Estado Novo para o esporte brasileiro, o CND (Conselho Nacional de Desportos), criado em abril de 1941, assume a função de fiscalizar e intervir na condução das políticas para o esporte no território nacional. (NEGREIROS, 1995). A partir da intervenção da CND, todas as entidades esportivas estavam obrigadas a possuir alvarás, estatutos modelares, registros oficiais, contabilidades e administrações controladas. Todo clube desportivo deveria filiar-se a federações competentes, que formariam as confederações subordinadas ao conselho nacional de desportos. De acordo com o estado: “Associação que não se filia não é de utilidade publica".

Assim sendo, não demorou para que estas medidas se espalhassem por todo o território nacional, chegando também à cidade de São João del-Rei que, para se adequar ao novo conselho esportivo nacional, viu-se obrigada a tomar medidas norteadoras para o esporte local. A principal delas foi a criação de uma nova liga municipal.

A LEOM, que até então geria o futebol na cidade, teria um prazo para se regularizar, como exigia a CND:

${ }^{4}$ Circular enviada a Liga Municipal pelo Governo - sem data exata 
os diretores da liga precisam ter um pouco mais de boa vontade, e convencer-se que precisam fazer a liga colocar-se juridicamente legal e filiá-la a uma liga legal (...). Todos os clubes que pertencem a liga não tem personalidade jurídica nem são legalmente constituído. Ahi vem a oficialização do esporte e no Rio de Janeiro já a CBD avisou e deu aos clubes o prazo ate o 31 deste para se legalizarem, caso contrario desaparecerão - o que será em Minas? Jornal DIÁRIO DO COMÉRCIO, 27 de maio de 1941, ano IV, n.970).

Por conseqüência, "em 14 de janeiro de 1944 pelos filiados Atletic Clube, Minas F. C. e América R. F.” é fundada a Liga Municipal de Desportos de São João del-Rei, tendo como seu primeiro presidente, Dario de Castro Monteiro 5 ". A liga, como foi instituído pelo governo, "obteve o seu primeiro alvará pela sua filiação na Federação Mineira de Futebol no dia 15/05/1944”. (ASSIS, 1985, p. 72).

As relações da Liga Municipal de Desportos com a imprensa são-joanense se davam por meio do jornal Diário do Comércio. Este virá a ser o responsável pela divulgação dos atos administrados da recém criada instituição, conforme a seguinte nota expedida, endereçada aos clubes filiados: "A Assembléia Geral da Liga resolveu marcar para o dia 19 de abril a realização do Torneio Initium de 1953” (Jornal DIÁRIO DO COMÉRCIO, 26 de Março de 1953. Ano. XVI, n. 4504, p. 2).

O jornal Diário do Comércio (1938 - 1965) torna-se em vista disso o principal veículo de divulgação do futebol na cidade, dedicando a este um espaço significativo na coluna denominada "Diário Esportivo". Era comum ver nestas sessões reclamações, análises e críticas sobre o esporte em São João del-Rei e no Rio de Janeiro. Em suas páginas eram comentados jogos e aquisições de jogadores de clubes como Vasco da Gama, Fluminense, Flamengo e Botafogo, deixando clara a forte influência do Rio de Janeiro, Capital brasileira na época, no futebol da cidade.

Os artigos esportivos do jornal Diário do Comércio eram todos opinativos, e o assunto em destaque era a profissionalização do futebol, considerada pela grande maioria, como a responsável pela decadência do esporte "bretão" na cidade e conseqüente diminuição da paixão e entusiasmo dos torcedores conforme texto publicado em 1941. Com o titulo de "A decadência do futebol" assim se expressa o articulista:

Afinal, qual a razão da decadência? São muitas. A maior é, sem duvida, o profissionalismo que estiolou o entusiasmo da mocidade. Dir-se-á, que, aqui não há profissionalismo e que, não obstante, o futebol perde a graça da população. Não há profissionalismo, mas há o reflexo do profissionalismo que faz com que não se pratique o futebol por esporte, mas simplesmente para se tornar um profissional. (Jornal DIÁRIO DO COMÉRCIO, 20 de Setembro de 1941, Ano IV, n. 1067, p. 4).

5 Ata da Liga Municipal de São João del-Rei de 27de abril de 1972 
Dentre os jornais analisados, o Diário do Comércio era o que buscava a maior aproximação entre os clubes e a população da cidade. De forma que era o único a promover, em vários momentos, uma interação maior com os leitores são-joanenses. Um exemplo foi o concurso ${ }^{6}$ realizado em 1952, objetivando eleger o clube mais popular de São João del-Rei. O relato apresentado indica que durante as votações na sede do jornal houve grande mobilização da população.

Outra fonte importante de pesquisa foi o jornal "O Correio" (1926 - 1960). Este periódico trazia críticas e crônicas a respeito do futebol na cidade. É importante ressaltar que na sessão "Correio Esportivo", diferentemente do Diário do Comércio, as notícias se referiam quase que exclusivamente ao esporte local, sendo raras as notas sobre acontecimentos esportivos ocorridos em outras cidades. Em comum com o Diário do Comércio, estava o fato das críticas serem dirigidas à decadência do futebol, como visto na citação a seguir:

Notamos, com certa tristeza mesmo, o descambar do foot ball em nossas canchas. Devido as rixas incomphreensiveis entre "teams" que, juntos, formariam um "scrater" quase invencível foi, dia a dia, por causa da animosidade acarretada sumindo todo aquele esplendor, todo aquele arrebatamento e enthusiamos provocados pelas liças footbolisticas, aqui em S. João. (...). Graças a tudo isso, a fallencia já ia atingindo também esta diversão, talvez a única, ora proporcionada, assim mesmo de quando em vez, aos sanjoannenses (Jornal O CORREIO, 21 de Junho de 1934. Ano VII, n. 406, p3).

Nesta reportagem é possível perceber que o cronista usa o seu ponto de vista para escrever a matéria. Essa era uma forte característica do jornal O Correio como podemos notar em uma crítica feita a alguns jogadores de futebol da época:

Focalizamos neste comentário, com o objetivo de realizar uma critica útil e oportuna, precisamente os "playeres" que não produzem para o conjunto, os que se detém em jogadas pessoais levando a prática de fintas inúteis por desnecessárias e importunas. Chegam alguns deles ao absurdo de se voltarem com a bola, a procura do adversário já vencido, na inqualificável intenção de fintá-lo novamente (Jornal O CORREIO, 24 de Julho de 1941. Ano XV, n. 879, p 5).

Outra característica importante do periódico era dar voz aos atores do futebol. Em uma seção denominada O "Crack da Semana" eram entrevistados os jogadores que se destacavam na rodada anterior do campeonato municipal. Eram feitas perguntas com relação à vida profissional e particular

${ }^{6} \mathrm{O}$ concurso foi disputado durante todo o ano de 1952, e teve seu resultado final divulgado na edição de 1 de Janeiro de 1953. O Minas Futebol Clube venceu com 39.973 votos seguido pelo Atletic Club com 21.726 votos. Na seqüência vieram o Ferroviário, Social, Olímpico, Milionários, Guarani, Cruzeiro, América, Esparta, Brasil, Siderúrgica e Municipal. 
de cada atleta. Através desta coluna, os leitores tinham a oportunidade de conhecer melhor os jogadores são-joanenses.

Entendemos que outra fonte importante, porém com poucos exemplares correspondentes ao período pesquisado, foi o jornal "A Tribuna" (1914 a 1938). Em uma coluna destinada às notícias do esporte, chamada de "Vida Sportiva", as crônicas trazidas pelo jornal eram sempre opinativas, como podemos notar no artigo assinado por Hildebrant de Magalhães e Plínio Campos da Silva:

Esta reportagem traz a historia de um redator da cidade de Barbacena que tentou alem de incentivar a rivalidade entre o Athletic e o Olympic através de falsas informações sobre a recepção são-joanense quando da vinda do clube barbacenense. No entanto, o povo de Barbacena não deu crédito ao redator. (...) $\mathrm{O}$ infeliz moço procurou fazer crer que, quando da visita do Olympic á S. João fora vitima de grosserias e promessa de valentia pelos nossos contemporâneos. (Jornal A TRIBUNA, 29 de Junho de 1930, Ano XVI, n. 1.029, p.2).

Nesta reportagem são observadas algumas singularidades dos redatores do jornal "A Tribuna". Não raro são encontrados comentários, às vezes, ofensivos a outros meios de comunicação da região, em especial a jornais. Fato este evidenciado pela reportagem extraída do citado jornal denominada "Gallos de Cruzeiros":

Vae acceso, o 'bate-boca' entre o pessoal da Tribuna e o O Correio. Se num domingo a Tribuna diz cobras e largatos d'O Correio, estes, no domingo seguinte diz uma porção de cousas d'Tribuna. E assim, as columnas mestras dos dois jornais conterrâneos, cujo o espaço poderia ser aproveitado para o ensino do cultivo das batatinhas inglesas, já que estas columnas ficam repletas de frazes invernizadas e irônicas pertencentes ao dito 'bate boca' (Jornal A TRIBUNA, 23 de Outubro de 1932, Ano XVIII, n. 1.138, p. 4).

Se por um lado a imprensa emitia opinião favorável à prática do futebol jogado nos clubes e organizado pela ligas esportivas, por outro, exprimia seu desagravo a esta mesma prática, levada a cabo nas ruas da cidade. Eram freqüentes as reclamações e manifestações de repúdio ao futebol que era praticado nas ruas da tradicional cidade mineira de origem colonial que buscava tornar-se moderna e civilizada:

Chamamos a atenção dos Sr.s guardas para o futebol da molecada no meio das ruas. Não há vidraças que resistam, vidros quebrados por todas as janelas. Um passeio, por piedade, de vez em quando na rua do comércio não seria mau, Srs. Guardas! (Jornal A TRIBUNA, 25 de Dezembro de 1930, Ano XVI, n. 1053, p. 3).

Sob os olhos indiferentes da policia vai se desenvolvendo pela cidade inteira a pratica do futebol nas ruas, causando danos e prejuízos a bens públicos e particulares (Jornal DIÁRIO DO COMÉRCIO, 27 de Dezembro de 1951, n. 4.130, p. 4). 
Tais queixas sobre o futebol nas ruas são feitas pelos principais jornais são-joanenses, contudo, em épocas diferentes. Sua prática era motivo de grande tormento já observado em décadas passadas conforme estudos realizados por Adão (2007). De acordo com os articulistas do jornal, os principais lugares para a prática do “desenfreado futebol” era na rua Dr. João Salestiano e na Praça Afonso Dale.

Este fato nos faz perceber a dualidade na forma em que o futebol era tratado pela imprensa. Enquanto que os jogos de futebol, ocorridos em estádios, eram vistos com bons olhos em São João del-Rei, "capaz de eletrizar multidões, na época em que mais valia ser presidente de clube que deputado" ", os jogos realizados nas ruas eram vistos como sinal de marginalidade, no qual era praticado "geralmente por moleques insubordinados que proferiam palavras ofensivas as pessoas de educação".

O futebol era assim visto como o esporte mais popular da cidade, porém sua prática clubística é apresentada pela pena do cronista como privilégio de uma parcela da população, uma vez que nem todos tinham condições de praticar o futebol organizado pelos clubes e pelas ligas esportivas, considerado como sendo prática de diversão regulamentada e bem quista pelos são-joanenses.

O que nos parece é que para a imprensa são-joanense, aqueles segmentos da população que não tinham condições de jogar o "Foot - Ball” nos clubes, não deveria fazê-lo em outro lugar, tornando-se apenas espectadores do esporte que apaixonava multidões. É certo que tal discussão abre margens para estudos futuros acerca da popularização parcial do futebol na cidade.

\section{Considerações Possíveis}

As relações entre a imprensa de São João del-Rei e o futebol se mostraram bastante estreitas. Dentre os principais jornais investigados é presente o espaço dedicado ao futebol manifestado através de comentários sobre a sua prática junto aos clubes locais.

Cabe destacar alguns dos pressupostos da teoria eliasiana que, tomados como referência, permitiu subsidiar elementos pertinentes a questões de pesquisa propostas no decorrer desta investigação. Para o estudo da relação imprensa e futebol em São João del-Rei, o conceito de configuração apresentou-se com pertinente por contribuir para a compreensão dos níveis de representação do futebol praticado pelos clubes e organizado pelas ligas esportivas ao longo das décadas de 1930 e 1940, deixando transparecer a maneira como sua prática era realizada e percebida pelos aficionados a partir dos relatos daqueles que escreviam nos jornais. Evidenciaram-se os níveis de tensão existentes entre as opiniões dos articulistas quanto a sua organização e a necessidade de criação de uma entidade capaz de gerir e organizar o chamado esporte bretão na cidade. Percebe-se também o

\footnotetext{
7 Trecho retirado do artigo intitulado: O poder do futebol, retirado do jornal O Correio de 7 de Junho de 1949, Ano XXII, Numero 2.229.

8 Trecho retirado de uma carta enviada ao jornal O Correio por um leitor, em 14 de Dezembro de 1939, Ano XIV, Numero: 717.
} 
debate levado a efeito pela imprensa em relação ao amadorismo e ao profissionalismo, expressando as tensões existentes neste campo. Neste sentido, a imprensa que acompanha o desenvolvimento do futebol local nas décadas de 1930 e 1940 apresenta-o inserido em uma configuração sócio-cultural que busca dotar a sua pratica de um caráter civilizatório. O intuito é vê-lo caminhando passo a passo com a cidade que aos poucos vai se industrializando e se modernizando, ainda que apegada as suas mais caras tradições.

O futebol como prática social quer ser constituir com prática civilizadora que demanda porém um novo enquadramento no que concerne a sua organização e, ainda, num reequilíbrio nas tensões evidenciadas entre os clubes, a Liga Municipal de Desportos e os indivíduos que administravam a sua prática. Neste sentido o arcabouço teórico conceitual propostos por Elias \& Dunning (1970) para analisar a inserção do esporte na sociedade demanda ainda compreender, na realidade estudada, os níveis de interdependência entre as práticas sócias tradicionais, (destaque para os festejos cívicos e religiosos) e as chamadas modernas diversões. O interesse crescente pelo futebol por parte dos indivíduos e da sociedade local vai ser objeto de calorosas discussões na imprensa, revelando os níveis de representação desse esporte na cultura são-joanense.

Tal como afirma Melo et alii (1997), acerca da relação esporte e imprensa no Rio de Janeiro, os clubes são-joanenses e a imprensa local também mantiveram uma relação marcada por momentos de boa convivência e tensão, uma vez que os interesses de ambos nem sempre convergiam quando o assunto era futebol. Por parte da imprensa, as reivindicações se davam no sentido da cobrança de maior envolvimento das agremiações esportivas na organização dos campeonatos e a redução da visão individualista dos clubes no sentido de, apesar dos interesses particulares, as rixas fossem amenizadas em prol do progresso do futebol local, que segundo a referida imprensa encontrava-se atrasado em relação ao que ocorria no restante do estado. Parecia evidente, apontam os jornais, o crescimento do futebol nas grandes cidades mineiras, neste sentido São João del-Rei, aspirante ao progresso e a modernização não deveria colocar-se atrás. A imprensa apontava como necessária a união das agremiações para a concretização de um objetivo comum, que segundo a mesma seria o fortalecimento do futebol local por meio do apoio as ligas existentes no período. Sem essa conjugação de interesses considerava-se que, dificilmente o futebol são-joanense superaria a improvisação e a recorrente falta de organização.

Observou-se ainda as intrigas geradas pelo futebol clubístico, as quais se expressam nas notas emitidas pelos redatores, quando deixam transparecer em seus comentários a preferência por esta ou aquela agremiação. Demonstrações estas que permitem indicar a dimensão apaixonada assumida pelos jornais em relação a prática do futebol local. 
Raramente as partidas eram noticiadas com imparcialidade cabendo destaque às agremiações consideradas maiores, as quais quase sempre ocupavam espaço maior na coluna esportiva. Foram observados ainda traços remanescentes dos primórdios do futebol em São João del-Rei, à medida os jornais apontam para as duas dimensões presentes no futebol local: de um lado a prática clubística, elogiada e incentivada, de outro o futebol considerado de rua, repudiado, visto com certo desprezo por ocasionarem prejuízo aos moradores dos largos e ruas próximas ao centro da cidade.

Ainda que cada jornal estudado possuísse características próprias no trato com as notícias, os mesmos foram importantes para divulgação do esporte na cidade. Através de noticias imparciais ou apaixonadas, os redatores/torcedores informavam a população os eventos esportivos da cidade, principalmente o futebol. Certo é, que a imprensa local nas décadas de 1930 e 1940 contribuiu a sua maneira para a consolidação do futebol como o esporte mais popular da histórica cidade de São João del-Rei.

\section{Fontes}

\section{Periódicos}

A Reforma, 1917.

Acção Social, 1915.

A Tribuna, 1919, 1930, 1932.

Cine-Ideal, 1919.

Diário do Comércio, 1939, 1940, 1941, 1951, 1953.

Folha Nova, 1932.

O Correio, 1934, 1941.

São João d'EL-Rey, 1920.

\section{Referências}

ADÃO, K. do S. (2001). Devoções e diversões em São João del-Rei: um estudo sobre as festas do Bom Jesus do Matosinhos em São João del-Rei - 1884 / 1924. Tese de Doutorado em Educação Física. Campinas, UNICAMP.

ADÃO, K. do S.; et alii. (2007). A cidade eclética e a festa "sportiva". In: Livro de Resumo e programação do XV Congresso Brasileiro de Ciências do Esporte e II Congresso Internacional de Ciências do Esporte. Recife: EDUPE. 
ALMEIDA, G. T. de. (1983). Imprensa do interior - um estudo preliminar. São Paulo: IMESP/DAESP.

ASSIS, A. (1985). Futebol em São João del-Rei. In: Revista do IHG. São João del-Rei. Vol. III.

COUTO, E. (2009). Entre chuteiras \& bengalas: história social do futebol em Belo Horizonte (1897-1927). Belo Horizonte: Quarto Setor.

CURY, M. Z. F. (1998). Horizontes modernistas: o jovem Drummond e seu grupo em papel jornal. Belo Horizonte: Autêntica.

ELIAS, N. (1994). A sociedade dos indivíduos. Tradução: Vera Ribeiro. Rio de Janeiro: Jorge Zahar. Edições 70. (1970). Introdução à sociologia. Tradução: Maria Luiza Ribeiro Ferreira. São Paulo: .; DUNNING, E. (1995). Deporte y ocio en el proceso de la civilizacion. México: Fondo de Cultura Econômica.

JUNIOR, C. L. M. (2009). Futebol e formação do espaço público no contexto da fundação do Coritiba Football Club (Curitiba, 1900-1915). Dissertação de Mestrado em Educação Física. Curitiba, UFPR.

MELO V. A. de; VEIGA, E. A. D. da; SALAZAR, F. N. (1997). O Esporte na Imprensa e a Publicidade Esportiva no Rio de Janeiro do Século XIX. In: Revista Brasileira de Ciências do Esporte. V.18, n.3.

MORORÓ, A. de C. (2009). Reflexões sobre as origens do futebol: uma revisão da literatura. In: Lazer, Esporte e Educação Física: Pesquisas e intervenções da Rede Cedes/UFJF. Juiz de Fora: Ed. UFJF.

MOURA, R. C. B. (2010). O amadorismo, o profissionalismo, os sururus e outras tramas: O futebol em Belo Horizonte nas décadas de 1920 e 1930. Dissertação de Mestrado em Educação Física. Belo Horizonte, UFMG.

NEGREIROS, P. J. L. de. (1995). Futebol no Estado Novo - algumas questões. In: Coletânea do III Encontro Nacional de História do Esporte, Lazer e Educação Física. Curitiba.

SANTOS, H. S. dos. (2009). Entre negros e brancos: considerações sobre a formação da cultura futebolística em salvador, 1901-1920. In: Recorde: Revista de História do Esporte. V. 2, n. 1, junho.

SANTOS, R. P. dos; SILVA F. C. T. da. (2006). Futebol e política, a construção de uma identidade nacional. (Memória Social dos Esportes II). Rio de Janeiro: Mauad: FAPERJ.

PIMENTA, R. D. (2009). Desvendando o jogo: o futebol amador e pelada na cidade e no sertão. Tese de Doutorado em Sociologia. Recife, UFPE. 